\title{
As atividades de extensão sob a ótica das relações de gênero: um estudo em uma universidade pública*
}

\author{
Natália Calderan Rissi** \\ Angela Maria Carneiro de Carvalho*** \\ Alessandra Rachid ****
}

\begin{abstract}
Resumo
O objetivo deste trabalho é analisar a participação das mulheres em atividades docentes em uma universidade pública, mais especificamente no âmbito das atividades de extensão. A coleta de dados foi realizada em um sistema interno de gestão de atividades de extensão e do sítio eletrônico de gestão de pessoas da universidade. Foram analisadas as participações feminina $e$ masculina nas atividades de extensão de sete departamentos, observando-se que as mulheres se concentram em áreas cujas atividades contam com menor aporte de recursos externos.
\end{abstract}

Palavras-chave: Universidade, Extensão Universitária, Trabalho Feminino, Professores Universitários.

\footnotetext{
* Recebido em 15 de março de 2017, aceito em 11 de abril de 2018.

** Pós-graduanda no Departamento de Engenharia de Produção da Universidade Federal de São Carlos, São Carlos, SP, Brasil. international.ufscar.nr@gmail.com / https://orcid.org/0000-0001-7670-4651

*** Docente no Programa de Pós-Graduação em Gestão de Organizações e Sistemas Públicos da Universidade Federal de São Carlos, São Carlos, SP, Brasil. acarvalho@dep.ufscar.br / https://orcid.org/0000-0002-0117-4518

**** Docente do Departamento de Engenharia de Produção da Universidade Federal de São Carlos, São Carlos, SP, Brasil. arachid@ufscar.br / https://orcid.org/0000-0003-2863-055X 
Extension Activities from a Gender Relations Perspective: a study at a public university

\section{Abstract}

The aim of this study is to analyze the participation of women in teaching activities at a public university, specifically related to extension activities. Data was collected from an internal management system for extension activities and the university website for personnel management. The participation of women and men in extension activities at seven departments was analyzed. It was found that women are concentrated in areas whose activities receive a lower contribution of external resources.

Keywords: University, University Extension, Female Work, Professors. 


\section{Introdução}

A partir da segunda metade do século XX, após o advento dos movimentos feministas, o "hiato de gênero na educação" começou a ser superado (Beltrão; Alves, 2009). Indicadores nacionais revelam que a representatividade feminina é maior que a dos homens dentre os estudantes nas universidades, mas não no mercado de trabalho e na ciência. O mesmo se observa entre docentes e pesquisadores das universidades brasileiras (Velho; Léon, 1997).

O objetivo deste trabalho é verificar a participação das mulheres em atividades de extensão que compõem, juntamente com o ensino e a pesquisa, as atividades centrais da universidade pública. Foram analisados os dados sobre participação feminina em sete departamentos acadêmicos de uma universidade pública que será chamada neste texto de UnPub, verificando se há ou não alguma distinção nessas atividades em relação aos recursos recebidos, comparando-as às atividades de extensão coordenadas por homens e com a maior participação masculina.

Além de observarmos o gênero de quem está à frente da coordenação dessas atividades, nosso objetivo também é analisar o gênero dos demais participantes das atividades (discentes de graduação ou pós-graduação, servidores técnico-administrativos e/ou membros da comunidade externa) e se receberam alguma remuneração em forma de bolsa.

A análise foi realizada à luz das discussões de segregação horizontal que marcam as distinções entre mulheres e homens no mercado de trabalho e na universidade e de sua concentração em diferentes áreas, e da segregação vertical ou "teto de vidro", que se remete às barreiras sutis e invisíveis que as mulheres têm que transpor para progredir em suas carreiras (Ichikawa; Yamamoto; Bonilha, 2008; Rigolin; Hayashi C.; Hayashi M., 2013; Vaz, 2013).

As três seções a seguir apresentam a revisão bibliográfica sobre algumas das principais interpretações relacionadas a segregação e desigualdade de gênero no mercado de trabalho, na formação feminina e no campo da ciência. Na quarta seção, 
apresenta-se a pesquisa realizada. $\mathrm{Na}$ quinta seção, estão os principais resultados e sua discussão.

As mulheres no mercado de trabalho: um cenário discriminatório

A discriminação é uma prática comum nas sociedades humanas, em qualquer tempo e em qualquer lugar, além de ser uma prática quase tão antiga quanto a própria existência humana. A discriminação é contrária ao princípio democrático da igualdade, pois se configura em externar ou materializar um preconceito (Lopes, 2000; Soares, 2000). Com o advento da internet, não é raro nos depararmos com manifestações $e$ comentários discriminatórios relacionados a questões religiosas, raciais ou de gênero.

A Organização Internacional do Trabalho (OIT) possui uma importante convenção (Convenção $\mathrm{n}^{\circ} 111$, de 1958), conhecida como a "Convenção sobre a Discriminação" do emprego e profissão (OIT, 1958). Em seu primeiro artigo, afirma que a discriminação não só compreende qualquer tipo de distinção, exclusão ou preferência a partir de raça, cor, sexo, religião, opinião política, nacionalidade ou efeito social, mas compreende também qualquer outro tipo de distinção, com base nesses elementos, que contribua para anular ou reduzir a igualdade de oportunidades e tratamento no emprego ou na profissão exercida.

Lopes (2000), com base em constatações da OIT, do Ministério Público do Trabalho, do Ministério do Trabalho e do Ministério da Justiça, apresenta três importantes formas de discriminação de gênero no mercado de trabalho: a) a justificativa de preterição das mulheres em promoções, tendo em vista que os colegas homens teriam dificuldades em aceitar uma mulher no comando; b) a demissão de mulheres por motivos de gravidez e/ou a exigência de um atestado de esterilização ou não gravidez no ato da contratação; c) o fato de as mulheres serem suscetíveis ao assédio sexual, como forma de pressão no ambiente laboral. Nesse sentido, a revista Exame (2014) informa que apenas $2 \%$ das 
mulheres ocupam o cargo de presidente e $7 \%$ ocupam cargos na diretoria operacional nas empresas brasileiras.

De acordo com Soares (2000), a discriminação existe porque há quatro grupos de trabalhadores dentro do mercado de trabalho: o grupo padrão, composto por homens brancos, os quais ditam as normas; o grupo de homens negros; o grupo de mulheres brancas; e o grupo de mulheres negras. Os três últimos são discriminados por não comporem o grupo padrão.

Nesse sentido, Bourdieu (2002) entende a dominação masculina como um "exemplo de excelência" sobre a violência simbólica exercida sobre o feminino. Para ele, a dualidade masculino versus feminino não justifica o caráter natural de dominação. Para o autor, as relações de gênero legitimam "uma relação de dominação inscrevendo-a em uma natureza biológica que é, por sua vez, ela própria uma construção social naturalizada" (2002:16). Portanto, ele entende que a superioridade masculina, baseada nas diferenças biológicas, é arbitrária.

Um ponto que chama a atenção é a contradição encontrada quando se compara o número de mulheres escolarizadas com o número de mulheres inseridas no mercado de trabalho. Conforme o relatório do Programa das Nações Unidas para o Desenvolvimento (PNUD) de 2013, a porcentagem de mulheres no mercado brasileiro é de 59,60\%, enquanto a de homens é de 80,90\% (Dana, 2014). Em contrapartida, Reith (2014) mostra-nos, de acordo com os dados obtidos no Censo Demográfico do IBGE de 2011, que 58\% das mulheres possuem ensino superior completo, enquanto os homens representam $42 \%$.

Em vista disso, se as mulheres são mais escolarizadas que os homens, não deveriam ter uma representatividade maior no mercado de trabalho? A resposta a essa pergunta deveria ser sim, entretanto a valorização da mulher escolarizada, com diploma, continua muito difícil. Isso ocorre por conta da discriminação de gênero, aliada a comportamentos culturais, reforçados por homens e mulheres em práticas cotidianas e entendidos como pertencentes a uma suposta e idealizada natureza feminina. Além disso, em especial as mulheres continuam assumindo maior 
responsabilidade pelas tarefas domésticas (Carvalho et alii, 2002), e, por isso, enfrentam maiores conflitos e obstáculos presentes na conciliação de sua vida pessoal e profissional (Vaz, 2013).

Outro indicativo que configura a discriminação de gênero é a comparação entre homens e mulheres com a mesma formação, já que a remuneração não é igualitária: a maior escolaridade das mulheres não foi suficiente para amenizar as diferenças de postos ocupados e nem de salários recebidos (Araújo; Lombardi, 2013). De acordo com a reportagem da revista Exame (2014), as mulheres ganham $30 \%$ a menos que os homens que desempenham a mesma função que elas no trabalho. A reportagem de Fábio (2015) argumenta que quanto mais alta a escolaridade, mais alta é a desigualdade de gênero: a diferença salarial entre homens $e$ mulheres com o ensino superior completo, no Brasil, chega a $38,13 \%$. Por fim, a diferença em termos de renda configura um dos mais importantes indicativos de desigualdade de gênero na América Latina, concluem Velho e Prochazka (2003).

A discriminação, associada às questões sociais discutidas anteriormente, é um dos fatores mais importantes no que diz respeito à questão da "segregação hierárquica" ou "segregação vertical" no mercado de trabalho, fenômeno conhecido também na literatura como "teto de vidro". A expressão, que surgiu na década de 1980 nos Estados Unidos, é uma metáfora que demonstra como as barreiras colocadas frente às mulheres são sutis e invisíveis, com fundo discriminatório e preconceituoso (Ichikawa; Yamamoto; Bonilha, 2008). Olinto (2011) reitera que essa segregação no ambiente de trabalho é o que explica a dificuldade que as mulheres têm de galgar posições de destaque na hierarquia organizacional.

Vaz (2013) também entende que esse fenômeno explica a lentidão com que as mulheres ascendem em sua carreira profissional, resultando em sua sub-representação em cargos de comando e, consequentemente, nas altas esferas do poder, do prestígio e das remunerações. Esse fenômeno ocorre mesmo em situações em que as mulheres possuem as mesmas características 
produtivas que os homens e gera, por consequência, um "afunilamento hierárquico" (Ethos, 2010).

De acordo com o Instituto Ethos, esse afunilamento aumenta quando se trata de atribuições de comando. Embora as mulheres representem $51,3 \%$ do total da população e $43,9 \%$ da população economicamente ativa, sua sub-representação é muito alta. A amostra, extraída pelo instituto, do grupo das 500 maiores empresas no Brasil mostra que: $26,8 \%$ das mulheres ocupam cargos de supervisão, $22,1 \%$ de gerência e apenas $13,7 \%$ no executivo.

Na esfera pública, em que as contratações são feitas por meio da aprovação em concurso, o "teto de vidro" parece ser menos evidente. No entanto, Vaz (2013) desconstrói essa ideia, pois afirma que essa falsa percepção colabora para que as mulheres permaneçam em escalóes inferiores. Em sua pesquisa, observa que, nos cargos de comissão do grupo direção $e$ assessoramento superiores (DAS) da administração pública federal, quanto mais alto o cargo, menor a participação feminina. Cabe explicar que os cargos de comissão DAS são de chefia e direção, preenchidos por nomeação.

Nas instituições de ensino superior, a pesquisadora constata que, de 2004 a 2007, a porcentagem de mulheres aumentou lentamente, passando de $41,4 \%$ para $43,7 \%$, muito embora apenas $40,9 \%$ desempenhassem a função docente com doutorado em período integral.

Nessa perspectiva, Carvalho (2016) observou que os maiores entraves enfrentados pelas mulheres bolsistas de produtividade do $\mathrm{CNPq}$ são a conciliação entre a vida profissional $e$ a vida familiar $e$ o ambiente científico androcêntrico. Esses obstáculos fazem com que as mulheres tenham dificuldades no convívio do dia-a-dia com os colegas homens e não tenham reconhecimento por sua capacidade, uma vez que são julgadas por não dedicarem $100 \%$ do seu tempo à pesquisa e à produção científica. Para a estudiosa, a permanência das mulheres no mundo científico ainda é um desafio. 
A segregação hierárquica nas instituições de ensino superior não é o único indício de desigualdade de gênero. A segregação horizontal, tratada a seguir, contribui para que essa desigualdade se mantenha também no campo da ciência.

A formação feminina e a segregação horizontal: a divisão sexual de carreiras

O estereótipo feminino presente ao longo dos séculos na sociedade patriarcal perdura até os dias atuais. A mulher ainda é vista como a maior responsável pelas atividades do lar e pela educação dos filhos, enquanto o homem é tido como o principal provedor do sustento da familia (Carvalho, 2016; Hayashi et alii, 2007; Lopes, 2000; Olinto, 2011; Soares, 2000; Reith, 2014; Vianna, 2001).

Esse estereótipo contribui para que a formação das mulheres, desde crianças, seja diferente da dos homens. Dessa forma, as meninas são estimuladas a brincarem de casinha e com bonecas, ou seja, desde muito cedo aprendem que seu lugar está junto do cuidado, da ternura, da subjetividade e da passividade. Delas espera-se a fragilidade, a submissão e a dedicação. Os meninos, por outro lado, são instigados com brinquedos de montagem de blocos, conferindo-lhes noção de espaço, autonomia e racionalidade. Aliás, os brinquedos tidos como masculinos podem ser entendidos como artefatos técnicos em miniaturas, como aviões, trens e carros. Deles, diferentemente das meninas, espera-se que sejam capazes de serem líderes $e$ autoconfiantes (Carvalho, 2016).

Para Olinto (2011), há muitos estudos que destacam e levantam informações sobre as diferenças de gênero numa perspectiva sociocultural $e$, para a autora, esses estudos demonstram o quão estereotipadas as mulheres são e como isso influencia em suas vidas:

Focalizam esses estudos em crenças, valores $e$ atitudes socialmente estabelecidos, que formam estereótipos sobre as habilidades diferenciadas entre homens $e$ mulheres $e$ 
influenciam as escolhas que as mulheres fazem cedo em sua existência, estabelecendo barreiras que limitam suas chances de vida (Olinto, 2011:69).

Desse modo, a segregação horizontal, marcada por essa divisão entre o que é feminino e masculino, leva as mulheres a escolherem caminhos $e$, futuramente, áreas de atuação muito divergentes dos caminhos que normalmente são escolhidos pelos homens. Afinal, a atuação exercida sobre elas, da própria família e da escola desde muito cedo, levam-nas a se autoavaliarem como mais capazes para exercerem atividades específicas. Portanto, ao se tornarem adultas, estabelecem estratégias de vida que são mais compatíveis com o que julgam ser mais adequado para si, ou seja, com o que se sentem mais predispostas a fazer. Consequentemente, pode-se inferir que esta predisposição ou aptidões tidas como femininas são culturalmente impostas. Uma ilustração válida sobre isso se dá na vida escolar, na qual faltam referências de grandes nomes femininos no mundo das ciências, deixando implícito que esse mundo não é da alçada feminina (Vianna, 2001; Olinto, 2011; Carvalho, 2016).

Harding (1993) ressalta que esse cenário reflete um sistema simbólico das relações de gênero, uma vez que os estereótipos de feminilidade e masculinidade são previamente delineados. Qualquer diferença ao agir, que não esteja marcada nesse sistema, atrai preconceito, indiferença e menosprezo.

Esse sistema simbólico das relações de gênero, baseado em estereótipos culturalmente determinados, permite compreender porque as carreiras da saúde, das artes e das ciências humanas são consideradas femininas (Godinho et alii, 2006). Isso reforça a tendência, apontada por Yannoulas, Vallejos e Lenarduzzi (2000), de que as mulheres fiquem agrupadas em disciplinas relacionadas a serviços. Por outro lado, as carreiras associadas às engenharias e à computação são tipicamente masculinas.

As engenharias fazem parte das chamadas "profissões imperiais", juntamente com o direito e a medicina, devido às "práticas monopolísticas que reforçaram suas posições de prestígio 
e estabeleceram barreiras frentes às demais profissões" (Vargas, 2010, s.p.).

O fenômeno de papéis sexuais distintos na carreira científica é conhecido como gender tracking (Velho; León, 1998). Essa tendência também pode ser observada na pós-graduação. A Tabela 1 mostra o número de doutores cadastrados na Plataforma Lattes, por área de atuação.

Tabela 1 - Distribuição de doutores por gênero e área de atuação (2015).

\begin{tabular}{|l|r|r|r|r|r|}
\hline Áreas & $\begin{array}{r}\text { Mulheres } \\
\text { (absoluto) }\end{array}$ & \multicolumn{1}{c|}{$\begin{array}{c}\text { Mulheres } \\
(\%)\end{array}$} & $\begin{array}{c}\text { Homens } \\
\text { (absoluto) }\end{array}$ & \multicolumn{1}{c|}{$\begin{array}{c}\text { Homens } \\
(\%)\end{array}$} & Total \\
\hline $\begin{array}{l}\text { Linguística, Letras } \\
\text { e Artes }\end{array}$ & 4.682 & $64,0 \%$ & 2.638 & $36,0 \%$ & 7.320 \\
\hline $\begin{array}{l}\text { Ciências } \\
\text { Biológicas }\end{array}$ & 8.832 & $57,7 \%$ & 6.477 & $42,3 \%$ & 15.309 \\
\hline Ciências da Saúde & 10.282 & $57,1 \%$ & 7.739 & $42,9 \%$ & 18.021 \\
\hline Ciências Humanas & 10.976 & $56,2 \%$ & 8.562 & $43,8 \%$ & 19.538 \\
\hline $\begin{array}{l}\text { Ciências Sociais } \\
\text { Aplicadas }\end{array}$ & 5.164 & $43,2 \%$ & 6.795 & $56,8 \%$ & 11.959 \\
\hline Ciências Agrárias & 4.732 & $39,5 \%$ & 7.248 & $60,5 \%$ & 11.980 \\
\hline $\begin{array}{l}\text { Ciências Exatas e } \\
\text { da Terra }\end{array}$ & 5.578 & $31,9 \%$ & 11.991 & $68,6 \%$ & 17.489 \\
\hline Engenharias & 2.772 & $24,7 \%$ & 8.431 & $75,3 \%$ & 11.203 \\
\hline Outra & 37 & $42,5 \%$ & 50 & $57,5 \%$ & 87 \\
\hline Não informado & 3.921 & $48,9 \%$ & 4.102 & $51,1 \%$ & 8.023 \\
\hline Total & 56.976 & $47,1 \%$ & 64.033 & $52,9 \%$ & 121.009 \\
\hline
\end{tabular}

Fonte: adaptado de Carvalho (2016).

Observa-se que as mulheres são grande maioria na área de Linguística e, também, nas áreas de Ciências biológicas, Ciências da saúde e Ciências humanas. No entanto, sua presença é menor nas demais áreas, ficando abaixo de $40 \%$ nas áreas de Ciências agrárias, Ciências exatas e da terra e, principalmente, nas engenharias, em que representam menos de $25 \%$. 
Historicamente, o acesso às instituições de ensino foi negado às mulheres (Hayashi et alii, 2007). Até os anos 1980, os homens eram mais escolarizados, mas, a partir dessa década, houve uma reversão dessa situação $e$ as mulheres se tornaram mais escolizadas que os homens (Beltrão; Alves, 2009). O acesso à educação fez com que as mulheres tivessem acesso também ao mundo da ciência, mas não de forma igualitária. Na seção seguinte, é abordada a presença das mulheres nesse espaço.

A presença das mulheres na ciência

O relatório feito pela organização internacional Organização de Cooperação e de Desenvolvimento Econômico (OCDE) em 2012 nos mostra o desempenho escolar de meninos e meninas. Enquanto os meninos são um pouco melhores em matemática, as meninas se mostram melhores em testes de leitura. Em ciências, o desempenho de ambos é equivalente. A partir desses dados, conclui-se que existe uma equidade de gêneros em relação ao desempenho escolar (Olinto, 2011). Olinto, ainda em referência ao mesmo relatório, aponta que as meninas são mais ambiciosas $e$ planejam seguir carreiras de maior prestígio do que os meninos. Segundo ela, isso ocorreu na maioria dos países considerados no estudo.

Mais tarde, quando essas meninas e esses meninos vão para o ensino superior, a maior escolaridade das mulheres fica evidente, visto que elas são a maioria em relação ao número de matrículas e de concluintes, como mostra a Tabela 2.

Tabela 2 - Porcentagem de homens e mulheres matriculados e concluintes no ensino superior (2015)

\begin{tabular}{|l|c|c|c|c|c|}
\hline & Homens & $\%$ & Mulheres & $\%$ & Total \\
\hline $\begin{array}{l}\text { Matrículas } \\
\text { Ensino } \\
\text { Superior }\end{array}$ & 3.438 .629 & $42,8 \%$ & 4.588 .668 & $57,2 \%$ & 8.027 .297 \\
\hline Concluintes & 443.558 & $38,6 \%$ & 706.509 & $61,4 \%$ & 1.150 .067 \\
\hline
\end{tabular}

Fonte: adaptado de INEP, 2015. 
Por outro lado, o número de mulheres na pós-graduação é significativamente menor que o de homens. Enquanto elas são $61,2 \%$ dos concluintes do ensino superior, representam apenas $47 \%$ do número de doutores cadastrados na Plataforma Lattes, como demonstra a Tabela 3.

Tabela 3 - Dados de doutores cadastrados na Plataforma

Lattes desagregados por sexo (2015)

\begin{tabular}{|l|c|c|c|}
\hline & Mulheres & Homens & Total \\
\hline Número Absoluto & 56.976 & 64.033 & 121.009 \\
\hline Porcentagem & $47 \%$ & $53 \%$ & $100 \%$ \\
\hline
\end{tabular}

Fonte: retirado de Carvalho (2016).

Os motivos porque as mulheres se apresentam em menor número na pós-graduação são inúmeros, como a dificuldade de obter financiamento, o casamento e a gravidez (Velho; Léon, 2007; Etzkowitz; Ranga, 2011; Costa, 2006).

Levando em conta esses argumentos, deve-se considerar também que há outros empecilhos enfrentados pelas mulheres no que diz respeito à sua ascensão na carreira científica. $O$ trabalho de Garcia e Sedeño (2006) sobre o assunto elenca três mecanismos de conservação das dificuldades encaradas por elas:

a) Elementos explícitos ou formais: são elementos institucionalizados, que normalmente refletem os valores éticos $e$ morais de uma sociedade;

b) Elementos ideológicos: são mecanismos culturalmente enraizados e internalizados, que as próprias mulheres reproduzem e dos quais não são conscientes (Olinto, 2011), como a ideia de inferioridade social e cognitiva perpetuada por muito tempo;

c) Elementos informais ou implícitos: são elementos sutis $e$ que de fato existem, colaborando para que as mulheres tenham que seguir trajetórias diferentes das dos homens. 
Essas trajetórias percorridas pelas mulheres no campo da ciência são denominadas de vanishbox. Esse termo pode ser interpretado como uma caixa da invisibilidade, na qual as mulheres estão inseridas (Etzkowitz; Ranga, 2011).

Como resultado de todas as considerações feitas até o momento, fica claro que o fenômeno "teto de vidro", referenciado na revisão bibliográfica, está inserido no mundo científico também. Afinal, as barreiras encontradas pelas mulheres impedem-nas, por exemplo, de participarem das conhecidas "redes informais de comunicação" (Etzkowitz; Ranga, 2011), que se fortalecem, normalmente, em ambientes informais $e$ em congressos. Por consequência, as mulheres ficam impedidas de acumular poder e influência, ficando em segundo plano (Carvalho, 2016).

A barreira sutil da invisibilidade feminina consolidada pelo fenômeno do "teto de vidro", de acordo com Olinto e Leta (2014), remete-nos ao conceito elaborado por Bourdieu (2003), conhecido como "capital científico". Para o estudioso, o capital científico é o prestígio e o reconhecimento alcançado pelos que fazem parte do mundo científico, que obedece a uma dinâmica social dos jogos de poder pertinente. Olinto e Leta (2014) observam que Bourdieu não aplica esse conceito às desigualdades de gênero com as quais as mulheres se deparam na ciência, o que seria perfeitamente adequado, uma vez que se refere a

disposições, hábitos e preconceitos enraizados e jogos de poder que atuam no ambiente científico afetando negativamente as oportunidades, o desempenho em diversas tarefas $e$ a produtividade da mulher na carreira científica (Olinto; Leta, 2014:2).

Portanto, o "teto de vidro", aliado à segregação horizontal, coloca as mulheres em posições desprestigiadas dentro das universidades, mesmo que públicas, devido à sua ausência nas esferas do alto poder dentro da própria carreira científica (Vaz, 2013). Isso significa que, se áreas de atuação no mercado de 
trabalho reconhecidas como femininas são desvalorizadas, as mesmas áreas no mundo científico também são (Olinto, 2011).

A pesquisa

A pesquisa que originou este artigo foi realizada em uma universidade pública, que aqui será chamada pelo nome fictício UnPub. A universidade possui 34 departamentos, que são organizados em três centros administrativos. Mais de $95 \%$ dos docentes têm doutorado e são contratados com regime de dedicação exclusiva.

Foi realizada uma coleta de dados sobre o número de docentes por departamento $e$ as atividades de extensão aprovadas entre 2013 e 2015. Para isso, foi utilizado o sítio eletrônico de gestão de pessoas da UnPub, para levantar o total de docentes em cada departamento, e o sistema que agrega as informações sobre as atividades de extensão. Os docentes, bem como todos os funcionários, são cadastrados de acordo com sua unidade de lotação e a informação fica disponível no sítio da UnPub, em um arquivo em pdf.

O sistema ligado à extensão foi desenvolvido para uso interno e pode ser acessado por servidores da universidade que se cadastrarem. Nesse sistema, as atividades de extensão são cadastradas uma a uma, por departamento, secretaria ou programa de pós-graduação. Nele, constam os dados sobre as atividades, quem as coordena, que tipo de atividade está sendo desenvolvido (consultoria, projeto, evento, curso, entre outras), data de início e término, tipo de recurso financeiro recebido, quem são os participantes, se recebem bolsa ou são voluntários, além de dados sobre as tramitações. Há, também, notificações sobre a aprovação ou dessas atividades, bem como o ano em que foram desenvolvidas.

Não há, no entanto, especificações sobre bolsas para docentes, assim como também não é possível saber o gênero de uma parte dos participantes, que são definidos depois da 
aprovação da atividade e que, portanto, são classificados no sistema como "indefinidos".

Para o estudo, foram selecionados dois departamentos de cada centro administrativo, considerando aqueles que tiveram o maior número de atividades de extensão que receberam auxílio financeiro, além do departamento de Engenharia de Produção, o terceiro com o maior número de atividades no seu centro administrativo e de interesse especial para as autoras. $\mathrm{O}$ auxílio financeiro pode ser externo, proveniente de agências de fomento, de órgãos públicos ou de empresas privadas; ou interno, proveniente da UnPub ou do departamento. A Tabela 4 apresenta o número de departamentos e de atividades aprovadas por cada centro administrativo, assim como o número de atividades dos departamentos selecionados.

Tabela 4 - Atividades de extensão aprovadas por centro administrativo da UnPub (2013 a 2015)

\begin{tabular}{|l|c|c|l|c|}
\hline \multirow{2}{*}{$\begin{array}{c}\text { Centro } \\
\text { administrativo }\end{array}$} & $\begin{array}{c}\mathrm{N}^{\circ} \text { de } \\
\text { departamentos }\end{array}$ & $\begin{array}{c}\text { Total de } \\
\text { atividades } \\
\text { aprovadas }\end{array}$ & $\begin{array}{c}\text { Departamentos } \\
\text { selecionados }\end{array}$ & $\begin{array}{c}\mathrm{N}^{\circ} \text { de } \\
\text { atividades }\end{array}$ \\
\hline $\begin{array}{l}\text { Ciências } \\
\text { humanas }\end{array}$ & 10 & 324 & Psicologia & 70 \\
\cline { 4 - 5 } $\begin{array}{l}\text { Engenharias e } \\
\text { exatas }\end{array}$ & 11 & 270 & Ciência da Informação & 44 \\
\cline { 4 - 5 } & 13 & 262 & Engenharia Civil & 61 \\
\cline { 4 - 5 } $\begin{array}{l}\text { Saúde e } \\
\text { biologia }\end{array}$ & 13 & $\begin{array}{l}\text { Engenharia de Materiais } \\
\text { Enfermagem }\end{array}$ & 57 \\
\hline
\end{tabular}

Fonte: elaboração própria.

Resultados

A UnPub conta com cerca de 900 docentes, $42 \%$ dos quais são mulheres. A Tabela 5 apresenta o número de docentes dos centros administrativos e dos departamentos selecionados para a análise. 
Tabela 5 - Número de docentes mulheres nos centros administrativos e nos departamentos selecionados

\begin{tabular}{|l|c|c|c|}
\hline \multicolumn{1}{|c|}{ Unidade } & No de docentes & No de mulheres & $\%$ \\
\hline \multicolumn{1}{|c|}{ Saúde e Biologia } & 241 & 150 & $62,2 \%$ \\
\hline Terapia Ocupacional & 25 & 24 & $96,0 \%$ \\
\hline Enfermagem & 23 & 23 & $100,0 \%$ \\
\hline \multicolumn{1}{|c|}{ Ciências Humanas } & 243 & 139 & $57,2 \%$ \\
\hline Psicologia & 46 & 32 & $69,6 \%$ \\
\hline Ciência da Informação & 16 & 10 & $62,5 \%$ \\
\hline \multicolumn{1}{|c|}{ Engenharias e Exatas } & 420 & 88 & $21,0 \%$ \\
\hline Engenharia Civil & 43 & 15 & $34,9 \%$ \\
\hline Engenharia de Materiais & 45 & 7 & $15,6 \%$ \\
\hline Engenharia de Produção & 43 & 8 & $18,6 \%$ \\
\hline
\end{tabular}

Fonte: elaboração própria.

Mesmo com o aumento do acesso feminino às universidades, cabe dizer que essa diferença entre homens $e$ mulheres ainda existe. Um dos motivos pode estar ligado ao fato de a carreira docente ser geralmente longa, sendo que as substituições no corpo docente levam tempo para ocorrer. A ausência de concursos regulares para a contratação de docentes apontada por Hayashi et alii (2007) pode ser mais um motivo, além daqueles discutidos na revisão bibliográfica, que restringiu o aumento da participação de mulheres no quadro de docentes da UnPub.

Por outro lado, ao interpretarmos os dados a partir da segmentação de áreas, é possível observar claramente a existência de uma segregação horizontal e de áreas mais masculinas ou mais femininas. O centro administrativo de Engenharias e Exatas possui 420 docentes, sendo que apenas $21 \%$ deles são mulheres. Essa segregação se repete nos departamentos pesquisados, se diferenciando apenas no departamento de Engenharia Civil, no 
qual a participação feminina é mais presente, representando $34,8 \%$ do corpo docente.

Historicamente, em consonância com o que foi discutido na revisão bibliográfica (Velho; Léon, 1998; Velho; Prochzka, 2003; Hayashi et alii, 2007), os homens são estimulados pela família, pela escola e pela sociedade a seguirem as carreiras relacionadas às ciências exatas. Os dados apresentados confirmam que as trajetórias universitárias são diferentes para homens e mulheres $e$ as carreiras mais vinculadas às engenharias permanecem predominantemente masculinas.

A segregação de gênero também ocorre nos centros administrativos de Saúde e Biologia e de Ciências Humanas, nos quais as mulheres representam $62,2 \%$ e $57,2 \%$, respectivamente. Os departamentos selecionados estão entre aqueles que apresentam maior representação feminina na universidade.

Essa diferença de gênero dá-se, conforme já apontado neste artigo, porque as mulheres são estimuladas a seguirem carreiras da saúde e da educação. Não parece coincidência que 10 dos 34 departamentos da UnPub apresentem maior número de mulheres nessas áreas.

A seguir, será apresentado o resultado obtido a partir do levantamento de dados das atividades de extensão dos departamentos selecionados.

A participação feminina nas atividades de extensão

As atividades de extensão, conforme determinado pelo Fórum de Pró-Reitores de Extensão de Universidades Públicas, em 1987, são um "processo educativo, cultural e científico que articula o ensino e a pesquisa de forma indissociável $e$ viabiliza a relação transformadora entre a universidade e a sociedade" (UFAL, s. d.). Através delas, pretende-se estabelecer uma relação entre a universidade e a comunidade ao seu redor, em que haja:

a) impacto $e$ transformação da comunidade, voltada para os interesses e necessidades de sua população; 
b) uma interação dialógica, para troca de saberes e extensão do conhecimento acadêmico, buscando superar desigualdades $e$ exclusão;

c) interdisciplinaridade, com o objetivo de estruturar o trabalho dos agentes sociais, através da interação entre modelos $e$ conceitos complementares, de material analítico $e$ de metodologias;

d) indissociabilidade do ensino, pesquisa e extensão, reafirmando as atividades de extensão como um processo acadêmico, uma vez que devem ser vinculadas ao "processo de formação de pessoas e de geração de conhecimento" (UNIRIO, s.d.).

$\mathrm{Na}$ UnPub, as atividades são coordenadas predominantemente por docentes e são divididas em seis 6 categorias:

- Integração entre ensino, pesquisa e extensão - oferecidas semestralmente à comunidade acadêmica, sendo abertas para o público em geral;

- Consultorias;

- Cursos: de especialização Lato Sensu, treinamento e qualificação profissional, presenciais ou à distância;

- Eventos;

- Publicações e produtos;

- Projetos: parcerias entre docentes e uma entidade pública ou privada externa.

A Tabela 6 apresenta a participação de mulheres docentes nas atividades de extensão dos departamentos selecionados. 
Tabela 6 - A participação das mulheres docentes na coordenação das atividades de extensão (2013 a 2015)

\begin{tabular}{|l|c|c|c|}
\hline \multicolumn{1}{|c|}{ Departamento } & $\begin{array}{c}\text { Atividades de } \\
\text { extensão com } \\
\text { recursos } \\
\text { financeiros }\end{array}$ & $\begin{array}{c}\mathrm{N}^{\circ} \text { de } \\
\text { atividades } \\
\text { coordenadas } \\
\text { por mulheres }\end{array}$ & $\%$ \\
\hline Terapia Ocupacional & 63 & 63 & $100,0 \%$ \\
\hline Enfermagem & 54 & 54 & $100,0 \%$ \\
\hline Total na área de saúde & 117 & 117 & $100,0 \%$ \\
\hline Psicologia & 70 & 64 & $91,4 \%$ \\
\hline Ciência da Informação & 44 & 31 & $70,5 \%$ \\
\hline Total na área de humanas & 114 & 95 & $83,3 \%$ \\
\hline Engenharia de Materiais & 57 & 6 & $10,5 \%$ \\
\hline Engenharia Civil & 61 & 6 & $9,8 \%$ \\
\hline Engenharia de Produção & 41 & 0 & $0,0 \%$ \\
\hline Total nas engenharias & 159 & 12 & $7,5 \%$ \\
\hline
\end{tabular}

Fonte: elaboração própria.

$\mathrm{Na}$ área de saúde, $100 \%$ das atividades de extensão são coordenadas por mulheres; nas humanas, 83,3\%, e nas engenharias, apenas $7,5 \%$. A desigualdade de gênero aqui parece ir além das explicações sobre a segregação horizontal e como ela determina quais carreiras são mais masculinas ou mais femininas. Nos departamentos com maior presença feminina, há uma porcentagem ainda maior de atividades coordenadas por mulheres, enquanto nos departamentos com maior presença masculina, há uma porcentagem ainda maior de atividades coordenadas por homens.

Cabe ressaltar, ainda, que as atividades de extensão mais comuns nas engenharias são diferentes daquelas executadas nas áreas de saúde e humanas. A Tabela 7 apresenta os dados sobre consultorias, que envolvem os maiores valores de financiamento externo, que variam de $\mathrm{R} \$ 900$ a $\mathrm{R} \$ 13$ milhões, e os cursos 
realizados, que podem envolver taxas pagas pelos alunos ou por empresas privadas, considerando os departamentos pesquisados.

Tabela 7 - Consultorias e Cursos (2013 a 2015)

\begin{tabular}{|l|c|c|c|c|c|}
\hline \multicolumn{1}{|c|}{ Área } & $\begin{array}{c}\text { Total de atividades } \\
\text { de extensão }\end{array}$ & Consultorias & $\begin{array}{c}\% \text { de } \\
\text { Consultorias }\end{array}$ & Cursos & $\begin{array}{c}\% \text { de } \\
\text { Cursos }\end{array}$ \\
\hline Engenharias & 159 & 56 & $35,2 \%$ & 51 & $32,0 \%$ \\
\hline Humanas & 114 & 7 & $6,1 \%$ & 30 & $26,3 \%$ \\
\hline Saúde & 117 & 9 & $7,6 \%$ & 5 & $4,2 \%$ \\
\hline
\end{tabular}

Fonte: elaboração própria.

Observa-se que os departamentos de engenharia apresentam $35,2 \%$ de suas atividades em consultoria e 32,0\% em cursos, quantidade bem maior que os demais departamentos. As engenharias permitem que os docentes estabeleçam contato com pessoas ligadas às empresas privadas, o que pode levá-las a contratar o serviço de consultoria.

Nos departamentos ligados à saúde, as consultorias e cursos somam apenas $14(11,8 \%)$ das 117 atividades, sendo que nenhum dos cursos é de especialização ou atualização e, portanto, não há cobrança de taxa. Entre as atividades de consultoria e cursos, apenas cinco $(3,1 \%)$ são coordenados por mulheres.

Os departamentos de humanas apresentam $6,1 \%$ atividades em consultoria, mas somente duas delas receberam financiamento externo: uma coordenada por um homem docente, que recebeu $\mathrm{R} \$ 360$ mil, e uma coordenada por uma mulher docente, que recebeu $\mathrm{R} \$ 5$ mil. Entre os 30 cursos $(26,3 \%)$ dessa área, apenas três envolvem o pagamento de taxa. Os demais são de atualização e financiados por órgãos públicos ou pela própria UnPub.

A Tabela 8 apresenta os projetos, eventos, atividades de integração entre ensino, pesquisa e extensão $e$ as publicações $e$ produtos, que, em sua maioria, são financiados pela própria UnPub, nos departamentos pesquisados. O valor dos recursos 
disponibilizados pela UnPub para cada uma dessas atividades de extensão é em torno de $\mathrm{R} \$ 1$ mil.

Tabela 8 - Atividades de extensão por centro (2013 a 2015)

\begin{tabular}{|l|c|c|c|c|c|c|}
\hline \multirow{2}{*}{\multicolumn{1}{c|}{ Atividade }} & \multicolumn{2}{|c|}{ Engenharias } & \multicolumn{2}{c|}{ Humanas } & \multicolumn{2}{c|}{ Saúde } \\
\cline { 2 - 7 } & Total & $\%$ & Total & $\%$ & Total & $\%$ \\
\hline Total de Atividades & 159 & $32,5 \%$ & 114 & $76,2 \%$ & 117 & $87,9 \%$ \\
\hline Projetos & 25 & $15,7 \%$ & 26 & $22,8 \%$ & 70 & $59,8 \%$ \\
\hline Eventos & 16 & $10,0 \%$ & 33 & $28,9 \%$ & 25 & $21,3 \%$ \\
\hline ACIEPEs & 8 & $5,0 \%$ & 26 & $22,8 \%$ & 4 & $3,4 \%$ \\
\hline Publicações e Produtos & 3 & $1,8 \%$ & 2 & $1,7 \%$ & 4 & $3,4 \%$ \\
\hline
\end{tabular}

Fonte: elaboração própria.

Como pode ser observado, os departamentos de engenharia pesquisados realizaram 52 dessas atividades, o que equivale a quase $32,5 \%$ do total de atividades desenvolvidas. A maioria das atividades de extensão dos departamentos da área de saúde é de projetos, $70(59,8 \%)$. Destes, 10 são financiados por órgãos públicos, como o Ministério da Saúde, e os repasses variaram de $\mathrm{R} \$$ 6,6 mil a $\mathrm{R} \$ 641,2$ mil. Assim como ocorre nos departamentos de humanas pesquisados, a maior parte das atividades é financiada pela própria UnPub e com recursos em torno de $\mathrm{R} \$ 1$ mil.

Também foi considerada a participação de mulheres docentes em outras posições e discentes, como bolsistas ou voluntárias. A Tabela 9 apresenta a participação feminina em atividades de extensão. 
Tabela 9 - A participação feminina nas atividades de extensão por departamento

\begin{tabular}{|l|c|c|c|c|c|c|c|c|c|}
\hline Departamento & \multicolumn{2}{|c|}{$\begin{array}{c}\mathrm{N}^{\circ} \text { de } \\
\text { atividad } \\
\text { es }\end{array}$} & \multicolumn{2}{|c|}{$\begin{array}{c}\text { Atividades com } \\
\text { coodenação } \\
\text { feminina }\end{array}$} & \multicolumn{2}{|c|}{$\begin{array}{c}\text { Atividades com } \\
\text { participação } \\
\text { feminina }\end{array}$} & \multicolumn{2}{|c|}{$\begin{array}{c}\text { Atividades } \\
\text { com bolsistas }\end{array}$} & \multicolumn{2}{|c|}{$\begin{array}{c}\text { Atividades } \\
\text { com bolsistas } \\
\text { mulheres }\end{array}$} \\
\hline $\begin{array}{l}\text { Terapia } \\
\text { Ocupacional }\end{array}$ & 63 & 63 & $100 \%$ & 63 & $100 \%$ & 54 & $85,7 \%$ & 54 & $\begin{array}{c}85,7 \\
\%\end{array}$ \\
\hline Enfermagem & 54 & 54 & $100 \%$ & 54 & $100 \%$ & 36 & $66,7 \%$ & 35 & $\begin{array}{c}64,8 \\
\%\end{array}$ \\
\hline Psicologia & 70 & 64 & $91,4 \%$ & 70 & $100 \%$ & 50 & $71,4 \%$ & 48 & $\begin{array}{c}68,6 \\
\%\end{array}$ \\
\hline C. Informação & 44 & 30 & $68,2 \%$ & 32 & $72,7 \%$ & 12 & $27,3 \%$ & 11 & $\begin{array}{c}25,0 \\
\%\end{array}$ \\
\hline Eng. Produção & 41 & 0 & $0,0 \%$ & 25 & $61,0 \%$ & 12 & $29,3 \%$ & 6 & $\begin{array}{c}14,6 \\
\%\end{array}$ \\
\hline Eng. Civil & 61 & 6 & $9,8 \%$ & 34 & $55,7 \%$ & 10 & $16,4 \%$ & 7 & $\begin{array}{c}11,5 \\
\%\end{array}$ \\
\hline Eng. Materiais & 57 & 6 & $10,5 \%$ & 24 & $42,1 \%$ & 14 & $24,6 \%$ & 8 & $\begin{array}{c}14,0 \\
\%\end{array}$ \\
\hline
\end{tabular}

Fonte: elaboração própria.

Observa-se que a participação feminina nas engenharias é menor que a dos homens, mas fica bem acima do que a participação de mulheres na coordenação. Na Engenharia de Produção, elas estão presentes em $61 \%$ das atividades; na Engenharia Civil, em 55,7\%; e na Engenharia de Materiais, em $42,1 \%$. No entanto, ainda é possível observar que muitas atividades de extensão ainda contam exclusivamente com a participação masculina. Nos departamentos de humanas e de saúde, a participação feminina nas atividades de extensão é quase de $100 \%$ nos departamentos considerados, sendo que somente na Ciência da Informação, a participação é menor, em $72,7 \%$ das atividades.

Não foi possível identificar, através do sistema, se os docentes recebem bolsa. As atividades que mais pressupõem a participação de discentes bolsistas são as atividades relacionadas a eventos e a projetos. Considerando que, nos departamentos de engenharia, há um menor número de atividades com a 
participação de mulheres $e$ que suas atividades são, majoritariamente, consultorias e cursos, é de se esperar que o número de bolsistas seja menor. Das 36 atividades com bolsistas, as mulheres estão presentes em 21 (58,3\%).

Nos departamentos de humanas, o número de discentes bolsistas é maior. Há a participação de bolsistas em 62 atividades, sendo que em 95,1\% delas há mulheres discentes. Pelo sistema, também foi possível observar que em 38 (61,3\%) das atividades com bolsa, a participação é exclusivamente feminina.

Nos departamentos da área da saúde, o número de bolsistas é maior. Das 117 atividades de extensão, 90 (76,9\%) contam com a presença de discentes bolsistas. Dessas atividades, 98,9\% têm bolsistas mulheres. Além disso, $72,2 \%$ das atividades possuem bolsistas exclusivamente mulheres.

$\mathrm{O}$ número de atividades de extensão com a presença de mulheres, sejam bolsistas ou não, demonstra que a maior presença das mulheres se dá em áreas do conhecimento que são socialmente conhecidas como femininas, como apontado pela literatura (Hayashi et alii, 2007; Rigolin et alii, 2013; Carvalho, 2016) e que ainda há um longo caminho a ser percorrido para que sua presença também seja notória em outras áreas do conhecimento, como as engenharias, em que a concentração masculina é maior.

Considerações finais

A análise da participação feminina nas atividades da extensão na universidade pesquisada, que demonstra a representatividade das mulheres no mercado de trabalho e na ciência, sugere que ainda há muito para avançar. Embora a porcentagem de mulheres com ensino superior completo seja maior que a de homens, esse cenário não se repete nas atividades de extensão desta universidade, confirmando que a permanência das mulheres no mundo científico $e$, consequentemente, na universidade, ainda é um desafio, como apontado por Carvalho (2016). 
Esta pesquisa se concentrou especificamente em atividades de extensão, sem considerar as tradicionais atividades de ensino $e$ pesquisa. As atividades de extensão são um dos pilares da universidade e permitem $\mathrm{o}$ acesso a fontes alternativas de recursos. A pesquisa dessas atividades foi possível devido ao sistema da universidade pesquisada, que permitiu o acesso aos dados relacionados à extensão.

Algumas tendências gerais no âmbito da literatura são confirmadas, como a concentração feminina nas áreas da saúde $e$ humanas, bem como a menor presença nas engenharias. Embora as mulheres estejam mais presentes dentro das universidades, levando em consideração a totalidade de docentes mulheres na universidade pesquisada $(41,7 \%)$ e, sobretudo, nos departamentos selecionados (49,3\%), observa-se que as mulheres ainda enfrentam dificuldades para ter visibilidade em algumas áreas.

Analisando no âmbito da extensão, foi possível observar que os docentes homens estão em maior número nas áreas cujas atividades envolvem maior volume de recursos financeiros, principalmente de origem privada. Por outro lado, as docentes mulheres concentram-se em áreas cujas atividades têm uma grande relevância social, mas que não contam com o mesmo aporte de recursos.

Na posição de coordenação dessas atividades, a disparidade é ainda maior. Nos departamentos com mais mulheres, sua presença na coordenação supera a proporção de mulheres observada nos próprios departamentos. Nos departamentos com mais homens, eles também estão mais presentes na coordenação do que nos próprios departamentos.

Quando se considera o total de participantes, no entanto, a disparidade diminui. Mesmo nos departamentos com maior presença masculina, as mulheres participam das atividades de extensão em proporção bem maior do que observado na coordenaçãa. Pode ser que, no futuro, essa participação abra caminho para que elas assumam mais posições de coordenação nestas áreas. 
A pesquisa considerou de forma mais detalhada as atividades de extensão de sete departamentos, ligados a diferentes áreas de conhecimento, selecionados por serem os que mais receberam auxílio financeiro no período de três anos. Uma pesquisa longitudinal, considerando um intervalo maior de tempo, seria interessante para observar se há tendência de mudanças ao longo do tempo. Também seria interessante considerar, em novas pesquisas, mais áreas de conhecimento, para confirmar se os resultados semelhantes são observados. Destaca-se, ainda, o interesse em pesquisas que ajudem a explicar a maior disparidade de gênero observada na coordenação destas atividades.

Referências bibliográficas

ARAÚJO, A. M. C.; Lombardi, M. R. Trabalho Informal, Gênero e Raça no Brasil do Início do Século XXI. Cadernos de Pesquisa, vol. 43, n'149, 2013, pp.452-477 [http://www.scielo.br/scielo.php?script=sci_arttext\&pid=S010015742013000200005 - acesso em 30 jul 2016].

Beltrão, K. I.; Alves, J. E. D. A reversão do hiato de gênero na educação brasileira no século XX. Cadernos de Pesquisa, vol. 39, n¹36, 2009, pp.125-156.

Bourdieu, P. A Dominação Masculina. Rio de Janeiro, Bertrand Brasil, 2002.

. Os usos sociais da ciência: Por uma sociologia clínica do campo científico. São Paulo, UNESP, 2003.

CARVAlHO, C. C. B. Equidade de gênero na ciência? Um estudo sobre as pesquisadoras bolsistas de produtividade da Universidade Federal de São Carlos. Dissertação (Mestrado Profissional em Gestão de Organizações e Sistemas Públicos), Universidade Federal de São Carlos, 2016.

Carvalho, J. L. F. S.; Carvalho, M. P. F. S.; Santos, L. C. Novas bonecas feitas de velhos retalhos: investigando medos, ansiedades $e$ inquietações das mulheres nas organizações. Anais do Encontro Anual da Associação Nacional dos Programas de Pós-Graduação em Administração - EnANPAD, vol. 27, 2002, pp. 1-15. 
Costa, M. C. Ainda somos poucas: exclusão e invisibilidade na ciência. cadernos pagu (27), Campinas-SP, Núcleo de Estudos de GêneroPagu/Unicamp, 2006, pp.455-459.

DANA, S. Mulheres e mercado de trabalho: uma discussão pendente. Folha de São Paulo, 25/03/2014.

ETHOS. Perfil social, racial e de gênero das 500 maiores empresas do Brasil e suas ações afirmativas - Pesquisa 2007. São Paulo, Instituto Ethos, 2010 [https://www3.ethos.org.br/cedoc/perfilsocial-racial-e-de-genero-das-500-maiores-empresas-do-brasil-esuas-acoes-afirmativas-pesquisa-2010/ - acesso em 14 ago 2016].

ETZKOWITZ, H.; RANGA, M. Gender dynamics in science and technology: from the leaky pipeline to the vanish box. Brussels Economic Review, Cahiers Economiques de Bruxelles, vol. 54, 2011. https://www.researchgate.net/publication/227379745_Gender_Dyn amics_in_Science_and_Technology_From_the_Leaky_Pipeline_to the_Vanish_Box. Acesso em 29/11/2018.

FÁBIO, A. C. Dois séculos separam mulheres e homens da igualdade no Brasil. Folha de S. Paulo, 29/09/2015.

Garcia, M. I. G.; Sedeño, E. P. Ciência, tecnologia e Gênero. In: Santos, L. W.; IChiKaWA, E. Y.; Cargano, D. de F. Ciência tecnologia e gênero. Londrina, IAPAR, 2006, pp.31-72.

GodinHO, T. et alii. Trajetória da mulher na educação brasileira: 19962003. Brasília, INEP, 2006.

HARDING, S. A instabilidade das categorias analíticas na teoria feminista. Revista Estudos Feministas, n¹, 1993, pp.7-31.

HAYASHI, M. C. P. et alii. Indicadores da participação feminina em ciência e tecnologia. TransInformação, vol. 19, n², 2007, pp.169187.

ICHIKAWA, E. Y.; YAMAMOTO, J. M.; BONILHA, M. Ciência, tecnologia e gênero: Desvelando o significado de ser mulher e cientista. Serviço Social em revista, vol. 11, $\mathrm{n}^{\circ} 1, \quad 2008$ [http://www.uel.br/revistas/ssrevista/ pdf/2008/18\%20Artigo\%20Genero_\%20ciencia_tecnologia\%20co rrigidos.pdf - acesso em 06 ago 2016].

INEP (INSTITUTO Nacional de Estudos e Pesquisas Educacionais Anísio Teixeira). Resumo técnico censo da educação superior de 2015. Brasília, MEC, INEP, 2015. 
[http://download.inep.gov.br/educacao_superior/censo _superior/resumo_tecnico/resumo_tecnico_censo_da_educacao_su perior_2015.pdf - acesso em 14 ago 2016].

LOPES, O. B. A questão da discriminação no Trabalho. Revista Jurídica, vol. $\quad 2, \quad \mathrm{n}^{\circ} 17, \quad 2000, \quad$ pp.1-8 [http://www.planalto.gov.br/ccivil_03/revista/rev_17/artigos/art_ota vio.html - acesso em 03 jul 2016].

MULHERES ainda são poucas e sem poder nas empresas. Revista Exame, 17 dez. 2014 [http://exame.abril.com.br/revista-exame/poucas-esem-poder/ - acesso em 07 ago 2016].

OCDE (ORGANIZAÇÃO PARA A COOPERAÇÃo E DESENVOLVIMENTO ECONÓMICO). Gender equality in education, employment and entrepreneurship: final report to the MCM, 2012 [http://www.oecd.org/education/48111145.pdf - acesso em 06 ago 2016].

OIT. Convenção sobre a Discriminação em Emprego e Profissão, 1958 [http://pfdc.pgr.mpf.gov.br/temas-de-atuacao/atuacao-econteudos-deapoio/legislacao/discriminacao/ai_discrim_emprego_profissao acesso em 30 jul 2016].

OLINTO, G. A inclusão das mulheres nas carreiras de ciência e tecnologia no Brasil. Inc. Soc., vol. $5 \mathrm{n}^{\circ} 1, \quad 2011$, pp.68-77 [http://revista.ibict.br/inclusao/index.php/inclusao/article/view/240 - acesso em 06 ago 2016].

OLINTO, G.; LETA, J. Gênero, geração e tarefas acadêmicas: investigando os docentes-pesquisadores dos programas de pós-graduação brasileiros. $4^{\circ} E B B C$ - Encontro Brasileiro de Bibliometria e Cientometria. Recife, 14 a 16 maio, 2014 [http://basessibi.c3sl.ufpr.br/brapci/index.php/article/download/271 89 - acesso em 13 ago 2016].

REITH, S. L. Programas de diversidade de recursos humanos: um estudo sobre sua adoção no Brasil. Dissertação (Mestrado em Engenharia de Produção), Centro de Ciências Exatas e de Tecnologia, Universidade Federal de São Carlos, 2014.

Rigolin, C.C.D.; HAYASHI, C.R.M.; HAYASHI, M.C.P. I. Métricas da participação feminina na ciência e tecnologia no contexto dos INCTs: primeiras aproximações. Liinc em Revista, vol. 9, $\mathrm{n}^{\circ} 1$, 2013,

pp. $143-170$ 
[http://revista.ibict.br/liinc/index.php/liinc/article/view/524 - acesso em 06 ago 2016].

SOARES, S. D. O Perfil da Discriminação no Mercado de Trabalho Homens Negros, Mulheres Brancas e Mulheres Negras. Diretoria de Estudos Sociais do IPEA, Brasília, 2000 [http://agencia.ipea.gov.br/pub/td/2000/td_0769.pdf - acesso em 06 ago 2016].

UNIVERSIDADE FEDERAL DO ALAGOAS. Extensão. [http://www.ufal.edu.br/estudante/extensao/o-que-e-extensao acesso em 17 set 2016].

Universidade Federal do ESTADO DO RIO DE JANEIRO. Diretoria de Extensão. [http://www2.unirio.br/unirio/proexc/dep.-deextensao/perguntas-frequentes - acesso em 17 set 2016].

VAZ, D. V. O teto de vidro nas organizações públicas: evidência para o Brasil. Economia e Sociedade, vol. 22, no3, 2013, pp.765-790. [http://www.scielo.br/pdf/ecos/v22n3/07.pdf - acesso em 14 ago 2016].

VARGAS, H. M. Sem perder a majestade: Profissões Imperiais no Brasil. Estudos de Sociologia, vol. 15, n 28, Araraquara, 2010, pp.107124.

VELHO, L.; LEÓN, E. A construção social da produção científica por mulheres. cadernos pagu (10), Campinas-SP, Núcleo de Estudos de Gênero-Pagu/Unicamp, 1998, pp.309-344. ; MoreirA, M. L. Pós-graduação do instituto nacional de pesquisas espaciais numa perspectiva de gênero. cadernos pagu (35), Campinas-SP, Núcleo de Estudos de Gênero-Pagu/Unicamp, 2010, pp.279-308.

; ProchazKa, M. V. No que o mundo da ciência difere dos outros mundos? ComCiência, Campinas, 2003. [http://www.comciencia.br/reportagens/mulheres/09.shtml - acesso em 21 ago 2016].

VIANNA, C. P. O sexo e o gênero da docência. cadernos pagu (17), Campinas-SP, Núcleo de Estudos de Gênero-Pagu/Unicamp, 2001 [http://www.scielo.br/pdf/cpa/n17-18/n17a03 - acesso em 11 set 2016]. 
YAnNoulas, S. C.; VAllejos, A. L.; LenARduZZI, Z. V. Feminismo e academia. Revista Brasileira de Estudos de Pedagogia, Brasilia, vol. 81, n$^{\circ} 199,2000$, pp.425-451. 